\title{
Bisphosphonates and lower mortality risk: when it sounds to be good to be true ...
}

\author{
W. D. Leslie ${ }^{1}$ (iD \\ Received: 4 September 2019 / Accepted: 5 September 2019/Published online: 19 October 2019 \\ (C) International Osteoporosis Foundation and National Osteoporosis Foundation 2019
}

Osteoporosis is a potentially lethal condition. Some of this excess mortality is attributable to the time-dependent increase in death that occurs in the aftermath of a fracture, particularly a hip fracture [1]. However, the factors that contribute to developing osteoporosis in the first place, including lifestyle (malnutrition, smoking, alcoholism) and medical comorbidities (too numerous to list) also increase mortality risk independent of any effect on fracture [2]. Indeed, mortality is highest in the first year after the fracture event and rapidly wanes with time, suggesting a decreasing proportion of deaths causally related to the fracture [3-5]. This complex interplay between fracture and death is explicitly modeled in the fracture risk assessment tool (FRAX) [6]. Indeed, when fracture probability is estimated in the presence of competing mortality the exponential agedependent increase in fracture risk is actually counteracted, reaching an inflection point around age 80 years, with a subsequent downturn [7].

Many studies show low bone mineral density (BMD) and/ or rapid BMD loss be associated with increased mortality risk [8-12]. Whether this is a causal or simply guilt by association-illness leading to weight loss, sarcopenia, impaired mobility, and frailty - is uncertain. To date, no bonederived factor has been identified that would explain why greater BMD would reduce mortality independent of fracture, or conversely a factor released during rapid bone catabolism that adversely affect survival. One provocative connection is the increasing evidence of shared risk factors between osteoporosis and atherosclerosis [13]. A large study that included 5590 at-risk subjects without known coronary artery disease (mean age 57 years, 69\% male) performed coronary artery calcium scoring and BMD measurements (four consecutive thoracic vertebrae, T7-T10) with follow-up for mean of

W. D. Leslie

bleslie@sbgh.mb.ca

1 Department of Medicine, University of Manitoba, C5121-409 Tache Avenue, Winnipeg, Manitoba R2H 2A6, Canada
8 years [14]. Increasing coronary artery calcification (CAC) severity correlated with lower BMD. Moreover, greater CAC and lower BMD were independently associated with the severity of $\mathrm{CAC}$ that in turn predicts mortality. A meta-analysis that included 46,182 participants from 10 studies (3991 allcause deaths, 1479 cardiovascular deaths, and 403 stroke deaths) found lower BMD to be associated with significantly increased risk of all-cause and cardiovascular mortality (pooled hazard ratio 1.20 per standard deviation decrease in hip BMD) [15].

It was therefore a surprising but welcome relief that against the backdrop of increased mortality in patients with osteoporosis that the HORIZON Recurrent Fracture Trial reported an unexpected "side benefit" for treatment with intravenous zoledronic acid following a hip fracture [16]. The safety analysis (but not a planned outcome) demonstrated a $28 \%$ relative reduction in all-cause mortality ( $13.3 \%$ placebo vs $9.6 \%$ zoledronic acid, $P=0.01)$. Inspection of the survival curves demonstrated no separation until approximately 16 months into the trial and then progressive separation out to 36 months. There was a non-significant trend to a reduction in death from cardiovascular causes $(4.9 \%$ vs $3.4 \%, P=0.10)$. The authors were appropriately cautious in interpreting this finding. A reanalysis of adjudicated cause of death by the blinded Central Review Committee confirmed that zoledronic acid was associated with a $25 \%$ reduction in mortality when adjusted for baseline fracture risk, and a $23 \%$ reduction in mortality when further adjusted for new clinical fractures (accounting for only $8 \%$ of the death benefit) [17]. Interestingly, when cause of death was examined, the primary benefit of zoledronic acid was in those with acute conditions (pneumonia and arrhythmia), a finding at variance with the late curve separation after 16 months. In contrast, the HORIZON Pivotal Fracture Trial in post-menopausal women with osteoporosis did not demonstrate a favorable mortality difference $(2.9 \%$ placebo vs $3.4 \%$ zoledronic acid, $P=0.27)$. Although women in the latter were at much lower mortality risk than in the fracture trial, the total numbers of deaths in both trials was identical, suggesting that 
statistical power was not the explanation. In fact, if the two HORIZON trials are pooled, then no significant mortality differences are seen $(5.4 \%$ placebo vs $4.9 \%$ zoledronic acid, $P=$ $0.3)$.

The experience with zoledronic acid sparked a systematic review and meta-analysis to see if this effect was detectable more broadly. Bolland et al. [18] searched for randomized placebo-controlled trials up to September 2008, and included 8 studies of 4 agents (risedronate, strontium ranelate, zoledronic acid, denosumab). Trials of estrogen and selective estrogen receptor modulators were excluded. The primary analysis found an $11 \%$ reduction in mortality that was nominally significant $(P=0.036)$. Similar results were seen in a metaanalysis of bisphosphonate for elderly patients with hip fracture in studies to January 2015 ( 2 randomized trials, 2 prospective trials) but this was dominated by the HORIZON Recurrent Fracture Trial [19]. A more recent meta-analysis examined cardiovascular outcomes in randomized controlled trials studies of bisphosphonates published to January 2016 (1991-2014, 61 included in the analysis) [20]. Although bisphosphonates had no effect on cardiovascular events (pooled relative risk (RR) in 20 trials 1.03 ; 95\% CI 0.91-1.17), there was a slight reduction in cardiovascular mortality (pooled RR in 10 trials $0.81 ; 95 \%$ CI 0.64-1.02) and significant reduction in all-cause mortality (pooled RR in 48 trials $0.90 ; 95 \%$ CI $0.84-0.98$ ). Subsequent reports have been observational with mixed findings. The most dramatic effect of osteoporosis treatment was in the subset of hip fracture patients randomized to case manager vs usual care who subsequently initiated oral bisphosphonate therapy where adjusted risk of death was reduced by $8 \%$ per month treated [21]. Of course, if such effects were real, then 1 year of therapy would produce quasi-immortality and bisphosphonates should be added to the drinking water!

The current issue of Osteoporosis International digs further into the question of confounding in observational studies reporting reduced mortality in bisphosphonate users. Bergman et al. [22] examined mortality in hip fracture patients identified through the Swedish Hip Fracture register using linked data on prescription medication dispensations through Swedish pharmacies. From the large number of hip fracture patient available, they selected individuals that were judged to meet the eligibility criteria for the previous zoledronic acid trial (49,765 of 260,574 patients), and then performed timedependent propensity score matching to identify 10,178 pairmatched bisphosphonate users and controls. Time from fracture to treatment initiation was not clear but was incorporated into the analysis through the time-dependent matching. The groups were extremely well matched for comorbidities that could impact on fracture risk as judged by conventional methods (standardized mean difference Cohen's $d<0.1$ ). Median follow-up was 2.8 years which is again similar to the previous clinical trial and the observed mortality $(29 \%)$ was also similar. Bisphosphonate users had a $15 \%$ lower mortality rate compared with matched controls. In contrast with the zoledronic acid trial, mortality curves separated early and this effect was seen in both the curves and hazard functions from day 6 onwards. The majority of the bisphosphonate therapy was with oral alendronate, with a small fraction of risedronate and zoledronic acid use. The authors concluded that bisphosphonate use was associated with lower mortality within days of treatment initiation. They proposed that this was consistent with confounding since there is no known pathway whereby oral bisphosphonate therapy should have such a rapid effect. Results were further assessed in relation to cause of death recorded in the Swedish register, which was similarly reduced across all categories including dementia/ Alzheimer's disease, defying a plausible biologic mechanism.

Clearly, the work of Bergman et al. [22] supports the presence of confounding in the observational data regarding bisphosphonate use and mortality. However, existence of bias does not exclude the possibility of a true effect of bisphosphonate treatment. I am pessimistic that there will be definitive evidence from a future clinical trial with mortality as the primary endpoint. Such a trial would be difficult to fund since generic bisphosphonates have changed the landscape in terms of funding large clinical trials, and the ethics of withholding treatment from high-risk individuals for many years is dubious. Cummings et al. [23] recently shed light on this subject in a comprehensive meta-analysis of randomized placebocontrolled trials. No significant mortality benefit was seen for all osteoporosis treatments combined (38 clinical trials, 45,594 placebo, 56,048 active therapy; risk ratio (RR) 0.98; 95\% CI, 0.91-1.05), bisphosphonates (21 clinical trials; 20,244 placebo; 22,623 active therapy; RR, 0.95; 95\% CI, 0.86-1.04), or zoledronate (6 clinical trials, 6944 placebo, 6926 active therapy; RR, 0.88; 95\% CI, 0.68-1.13).

In summary, it should be reassuring to healthcare providers and patients that mortality risk is certainly no higher with bisphosphonate therapy, offering a refreshing counterpoint to the barrage of "bad news" in the media [24, 25]. But much as my heart longs for a good news story and to believe that bisphosphonates are the elixir of life that can prevent death regardless of cause, my brain whispers "When it sounds too good to be true..."

\section{Compliance with ethical standards}

Conflicts of interest None.

\section{References}

1. Schousboe JT (2017) Mortality after osteoporotic fractures: what proportion is caused by fracture and is preventable? J Bone Miner Res 32(9):1783-1788 
2. Teng GG, Curtis JR, Saag KG (2008) Mortality and osteoporotic fractures: is the link causal, and is it modifiable? Clin Exp Rheumatol 26(5 Suppl 51):S125-S137

3. Kanis JA, Oden A, Johnell O, De Laet C, Jonsson B (2004) Excess mortality after hospitalisation for vertebral fracture. Osteoporos Int 15(2):108-112

4. Johnell O, Kanis JA, Oden A, Sernbo I, Redlund-Johnell I, Petterson C et al (2004) Mortality after osteoporotic fractures. Osteoporos Int 15(1):38-42

5. Morin S, Lix LM, Azimaee M, Metge C, Caetano P, Leslie WD (2011) Mortality rates after incident non-traumatic fractures in older men and women. Osteoporos Int 22(9):2439-2448

6. Kanis JA, Johansson H, Oden A, McCloskey EV (2009) Assessment of fracture risk. Eur J Radiol 71(3):392-397

7. Kanis JA, Harvey NC, Johansson H, Oden A, McCloskey EV, Leslie WD (2017) Overview of fracture prediction tools. J Clin Densitom 20(3):444-450

8. Domiciano DS, Machado LG, Lopes JB, Figueiredo CP, Caparbo VF, Oliveira RM et al (2016) Bone mineral density and parathyroid hormone as independent risk factors for mortality in communitydwelling older adults: a population-based prospective cohort study in Brazil. The Sao Paulo Ageing \& Health (SPAH) Study. J Bone Miner Res 31(6):1146-1157

9. Johansson H, Oden A, Kanis J, McCloskey E, Lorentzon M, Ljunggren $\mathrm{O}$ et al (2011) Low bone mineral density is associated with increased mortality in elderly men: MrOS Sweden. Osteoporos Int 22(5): 1411-1418

10. Suzuki T, Yoshida H (2010) Low bone mineral density at femoral neck is a predictor of increased mortality in elderly Japanese women. Osteoporos Int 21(1):71-79

11. Nguyen ND, Center JR, Eisman JA, Nguyen TV (2007) Bone loss, weight loss, and weight fluctuation predict mortality risk in elderly men and women. J Bone Miner Res 22(8):1147-1154

12. Kado DM, Browner WS, Blackwell T, Gore R, Cummings SR (2000) Rate of bone loss is associated with mortality in older women: a prospective study. J Bone Miner Res 15(10):1974-1980

13. Rodriguez AJ, Scott D, Ebeling PR (2019) Exploring the links between common diseases of ageing - osteoporosis, sarcopenia and vascular calcification. Clin Rev Bone Miner Metab 17(1):1-23

14. Ahmadi N, Mao SS, Hajsadeghi F, Arnold B, Kiramijyan S, Gao Y et al (2018) The relation of low levels of bone mineral density with coronary artery calcium and mortality. Osteoporos Int 29(7):1609_ 1616
15. Qu X, Huang X, Jin F, Wang H, Hao Y, Tang T et al (2013) Bone mineral density and all-cause, cardiovascular and stroke mortality: a meta-analysis of prospective cohort studies. Int J Cardiol 166(2): 385-393

16. Lyles KW, Colon-Emeric CS, Magaziner JS, Adachi JD, Pieper CF, Mautalen C et al (2007) Zoledronic acid and clinical fractures and mortality after hip fracture. N Engl J Med 357(18):1799-1809

17. Colon-Emeric CS, Mesenbrink P, Lyles KW, Pieper CF, Boonen S, Delmas P et al (2010) Potential mediators of the mortality reduction with zoledronic acid after hip fracture. J Bone Miner Res 25(1):9197

18. Bolland MJ, Grey AB, Gamble GD, Reid IR (2010) Effect of osteoporosis treatment on mortality: a meta-analysis. J Clin Endocrinol Metab 95(3):1174-1181

19. Peng J, Liu Y, Chen L, Peng K, Xu Z, Zhang D et al (2016) Bisphosphonates can prevent recurrent hip fracture and reduce the mortality in osteoporotic patient with hip fracture: a meta-analysis. Pak J Med Sci 32(2):499-504

20. Kranenburg G, Bartstra JW, Weijmans M, de Jong PA, Mali WP, Verhaar HJ et al (2016) Bisphosphonates for cardiovascular risk reduction: a systematic review and meta-analysis. Atherosclerosis. 252:106-115

21. Beaupre LA, Morrish DW, Hanley DA, Maksymowych WP, Bell NR, Juby AG et al (2011) Oral bisphosphonates are associated with reduced mortality after hip fracture. Osteoporos Int 22(3):983-991

22. Bergman J, Nordström A, Hommel A, Kivipelto M, Nordström P. Bisphosphonates and mortality: confounding in observational studies? Osteoporos Int. 2019; in press.

23. Cummings SR, Lui LY, Eastell R, Allen IE (2019) Association between drug treatments for patients with osteoporosis and overall mortality rates: a meta-analysis. JAMA Intern Med

24. Jha S, Wang Z, Laucis N, Bhattacharyya T (2015) Trends in media reports, oral bisphosphonate prescriptions, and hip fractures 19962012: an ecological analysis. J Bone Miner Res 30(12):2179-2187

25. Khosla S, Cauley JA, Compston J, Kiel DP, Rosen C, Saag KG et al (2016) Addressing the crisis in the treatment of osteoporosis: a path forward. J Bone Miner Res

Publisher's note Springer Nature remains neutral with regard to jurisdictional claims in published maps and institutional affiliations. 